Ethnography and Education, 2013

Vol. 8, No. 2,

146161, http://dx.doi.org/10.1080/17457823.2013.792505

S.Allendyke@mmu.ac.uk

Sylvie Allendyke formerly Sarah Dyke ESRI MANCHESTER METROPOLITAN UNIVERSITY 


\title{
Utilising a blended ethnographic approach to explore the online and offline lives of pro-ana community members
}

\author{
Sarah Dyke*
}

Education and Social Research Institute, Manchester Metropolitan University, Manchester, UK

The article critically interrogates contemporary discourses and practices around anorexia nervosa through an ethnographic study that moves between two sites: an online pro-anorexia (pro-ana) community, and a Local Authority-funded eating disorder prevention project located in schools and youth centres in the north of England. The article challenges the binary distinctions that are often made between anorexia as a serious mental illness on the one hand, and mere lifestyle choice on the other, and argues for a more nuanced and complex understanding of the dilemmas, practices and emergent subjectivities of those who experience a difficult relation to feeding the body. Similarly, the article challenges methodological distinctions between empirical ('real-life') and online or virtual ethnography. It demonstrates how the research participants moved between online and offline presence, and attempts to develop a mobile and connective ethnographic methodology that is similarly attuned to both the actual and the virtual, without separating or prioritising one over the other. The article suggests that educational interventions aimed at reducing the incidence of eating disorders, whether in schools or informal settings, are likely to be ineffective if they do not recognise the complex interweaving of virtual and online activity in the daily lives of young people. Moreover, it is argued that current educational interventions aimed at tackling problematic eating behaviours risk being marginalised as a result of educational priorities that place the core curriculum and national testing at the top of schools' agendas in England. The intervention project described here suffered from perceptions of low priority by school staff, and a tendency to allocate students to the project who had been identified as poorly behaved or as low achievers, rather than according to considered view of need. Paradoxically therefore, young people who may be experiencing a difficult relation to feeding the body appear to be a subject both of high anxiety and low priority.

Keywords: connective/mobile ethnography; blended methodology; pro-anorexia; wannarexia; anorexia nervosa

\section{Introduction}

This article challenges contemporary assumptions about the diagnosis, status and treatment of young people who experience a difficult relation to feeding the body and explores the implications for educational interventions involving young people in schools and informal education settings. The arguments are based on an ethnographic study that moved between two sites: an online pro-anorexia (pro-ana) community, and a Local Authority-funded eating disorder prevention project located in schools and youth centres in the north of England. I challenge the binary 
*Email: S.Dyke@mmu.ac.uk

\# 2013 Taylor \& Francis

distinctions that are often made between anorexia as a serious mental illness on the one hand, and mere lifestyle choice on the other, and engage with both lifestyle choice and illness as a productive paradox rather than a contradiction.

Similarly, the article challenges methodological distinctions between empirical ('reallife') and online or virtual ethnography. It demonstrates how the research participants moved between online and offline presence and develops a mobile and connective ethnographic methodology an approach which is "agnostic about "real" places and categories' (Hine 2000,62). Within connective ethnography, rather than defining the field site at the outset of the project, the field is incrementally defined or bounded (Markham 2008) as the researcher follows the traces of the phenomena they seek to illuminate. This method enables the researcher to work with, notice and find interesting those unexpected flows which arise in the research process, rather than fearing them as transgressions of 'proper' research design.

Anorexia nervosa: definitions and assumptions

Anorexia nervosa is considered a serious mental illness. The Diagnostic Statistical Manual-IV (DSM-IV; APA 2000) classifies it according to four criteria: a refusal to a maintain body weight at or above $85 \%$ of normal weight for age and height; an intense fear of gaining weight or becoming fat; a disturbance in the way in which one's body weight or shape is experienced; and amenorrhoea, i.e. the absence of at least three consecutive menstrual cycles. ${ }^{1}$ Anorexia has the highest mortality rate of any psychiatric illness and its amenability to treatment remains especially challenging (Gremillion 2003). It is largely thought to affect women more commonly than men, and the onset period is thought to most commonly occur during adolescence (Royal College of Psychiatrists, 2009). Links have also been made between anorexia and higher levels of educational achievement (Lawrence 1987) and class (Darmon 2009).

As a category anorexia nervosa is primarily considered therefore through a medical and psychiatric discourse as a definable, diagnosable 'biologically based serious mental disorder' (Klump et al. 2009). Anorexia nervosa, as a proper name and a 'real category' within the Diagnostic Statistical Manual, affects the few: it is rare.

However, since the early 2000s, this 'proper name' has been reinscripted (Bray 1996) by online pro-anorexia or 'pro-ana' communities. In the move from anorexia nervosa to pro-ana, that which was considered rare, and adjudicated by medical discourse, becomes the prerogative of a much wider community of online 'experience based experts' (Collins and Evans 2002). Online authenticity and expertise shift a move that is identifiable across health-related sites in general, where previously individualised consumers of knowledge become collective producers of expert knowledge (Conrad and Stults 2010).

This movement, and the advocacy that the 'pro' in pro-ana implies, goes some way to challenge the idea that the phenomenon and object of inquiry, 'anorexia nervosa', should remain 'fixed' only as a mental illness, and also that the way in which we think and theorise it should remain dutiful to scientific and medical expertise. If we look no further than this medicalised representation of anorexia, indeed take it as our starting point for social research, the focus, as with three of the four criteria used to diagnose it, becomes about weight and appearance. As will be argued throughout the paper, this attention to physical representations of anorexia obscures the everyday relationship to feeding the body which 


\section{S. Dyke}

is incremental in its development and difficult well in advance of the ascription of the 'proper name' of anorexia nervosa.

By working with the idea of 'illness', albeit ambivalently and critically, this paper connects to other work which explores illness in the age of the Internet (Conrad and Stults 2010; Day and Keys 2008; Fox and ward 2006; Miah and Rich 2008; Mulveen and Hepworth 2006).

The online presence of pro-ana

According to the medical discourse, as noted above, anorexia is a rarity affecting roughly $1 \%$ of the population. However, if we regard online life as equally constitutive of 'real life' as that which takes place offline (Markham 1998), this figure, which has remained fixed for years, is troubled by the marked rise in pro anorexia websites during the last decade. According to an international IT security company, between 2006 and 2008 there was a $470 \%$ increase globally in pro-ana sites (Optenet 2008), a figure which should of course be contextualised within the rise in internet usage more generally. According to World internet statistics used by Conrad and Stults (2010) internet usage reached 1.5 billion in 2007, a figure which has increased further to just under 2.5 billion in 2012 (World Internet Statistics 2012). However, rather than diminishing the significance of the increase in pro-ana sites, this general increase in online activity suggests the need for methodologies that recognise the validity, vitality and significance of online life and its complex interconnections with life offline. This is especially important, I suggest, when researching areas where embodiment is significant, such as gender, bullying, sexuality or feeding the body.

Everyday life is increasingly technologically mediated (Murthey 2008; Rheingold 1993) and health-related websites and discussion forums are noted as some of the most popular resources on the Internet (Miah and Rich 2008). It would not be outlandish to suggest that those who enter into online engagements with 'disordered eating' now number in their millions. Moreover, the highest users of internet resources for health-related purposes appear to include women, younger people and those with higher levels of education (Fox, cited in Conrad and Stults 2010). In addition, stigmatised illnesses, especially psychiatric illnesses, appear to be factors which drive internet usage (Conrad and Stults 2010). High internet use by young, well-educated women thus apparently coincides with the population who are most often deemed at risk of developing eating disorders. The number of persons engaging in pro-ana discussions, learning how to do or become anorexic by exploring the 'tips and tricks' sections of the sites, or maintaining an existing way of being with the help and support of others (Dias 2003; Gavin, Rodman, and Poyer 2008) is very likely therefore to be in excess of the number of 'real' or 'proper anorexics' that the DSMIV identifies.

While I do not suggest that internet and online communities entirely bring about the desire of subjects to collude in or 'choose' anorexic becomings, they do engender a discursive 'space' for anorexia to be articulated differently and to include embodied experience as a source of knowledge and expertise (Conrad and Stults 2010). Rather than only being an illness with a proper name, Anorexia also becomes Ana: a communally meaningful 'aspirational lifestyle choice' (Dias 2003; Fox, Ward, and O'Rourke 2005) which extends beyond the parameters of individualising and pathologising discourses. Indeed Hammersley and Tresseder note that some sites go so far in their challenge to the medical discourse and its powerful expertise as to take a 'strident, human rights stance' $(2007,291)$. In other words they assert that it is a human right to choose the way in which 
one's life is lived and to refuse normalising procedures, even when this includes practices which involve risks to physical wellbeing.

The pro-ana community is both marginal and heterogeneous. It is not without contestation and antagonism abounds both internally, between site users (Giles 2006) and externally from both the general public and the media (Ferreday 2003; Pollack 2003; Dias, 2003; Fox, Ward, and O'Rourke 2005). Ferreday suggests that the proana community has attracted more criticism and controversy than any other online community, citing the 'notorious' yahoo case of 2001 where all pro-ana sites were removed from the Internet server (2003, 283. Also see Dias 2003; Pollack 2003).

However, this paper focuses primarily on internal antagonism and contestation which emerged online during the course of my own empirical work.

Although my work does not advance the idea that Anorexia is only a fixed 'illness' with a proper name, I do not dismiss the idea entirely, even when it is my contention that embodied choice, collusion and desire all flow into and out of this object of inquiry. Methodologically I am able to work with the idea of illness by conceiving it as one aspect of a productive paradox which, as a theme, helped me to border my field of inquiry (Markham 2008). It is not that new information replaces previous knowledge, but rather that as spaces of communing and communicating open up online, so do taken for granted and familiar ways of understanding phenomena and subjectivities. Medical expertise is not replaced by experts with embodied experience. Rather, these epistemologies brush up against one another producing different possibilities.

We must also note the significance of power and powerful discourses. Although medical expertise is contested in pro-ana communities, it is also mobilised in the context of discussions about what 'proper anorexia' is. Speaking through the medical discourse, be it by a medical professional or a pro-ana, implies speaking with and through power and authority.

Design and conduct of the research

Ethnographers' might still start from a particular place, but would be encouraged to follow connections which were made meaningful from that setting. The ethnographic sensitivity would focus on the ways in which particular places were made meaningful and visible. Ethnography in this strategy becomes as much a process of following connections as it is a particular period of inhabitance. (Hine 2000, 60)

In the course of my research, I found myself adopting the connective methodology described by Hine above, as I followed the movements of the research participants, and 'anorexia' through online and offline spaces. As Hine suggests, although we may start from one place, perhaps somewhere offline like a youth work project or an after school club, as in the case of my research, as we engage sensitively with participants and their daily lives, online spaces, activities, practices and communities can become meaningful. Rather than conceiving the virtual as outside the scope of 'proper' ethnographic interrogation or disruptive to the boundaries of 'the field', I attempted to develop ways of engaging with the virtual, and blending it into fieldwork, data collection, field notes and research diary to produce new ways of making the familiar strange and the strange familiar (Geertz 1993).

From the outset of my project I had wanted to give a different, unfamiliar, account of anorexia. I wanted to find a way of acknowledging the mundane and everyday 


\section{S. Dyke}

management of a difficult relationship to feeding the body. As Rich (2006) notes, there is a scarcity in academic literature of day-to-day accounts of disordered eating. In contrast to received medical and media discourses, I started from the assumption that emaciation might be the least important, rather than the most important consideration.

My mobile or connective ethnography began from two spaces. Offline I became involved as a participant observer in an eating disorder prevention project, while online I began to explore pro-anorexia sites for themes and ideas which would help me to refine the parameters of my engagement with the research object or 'border the field'.

The prevention project

The prevention project was commissioned by a youth work organisation based in the north of England with funding from the local authority. The scope of the project was to initially map Tier $1^{2}$ provision (i.e. professionals who are not mental health specialists) in the locale, in a bid to reduce the number of children and young people who were being diagnosed and hospitalised at Tier 4 of the Child and Adolescent Mental Health Services (CAHMS). The commission also involved developing and delivering a programme of activities focused on raising self-esteem (McGee and Williams 2000) and challenging images of 'the thin ideal' in the media (Chaote 2005). As a participant observer I attended team and project planning meetings and visited schools and youth centres with the project coordinator and the lead youth worker. This enabled me to see how prevention was put into practice.

As already noted, pro-ana sites have proliferated rapidly in recent years. Indeed, in a study of 13 - to 17 -year-old schoolchildren, $12.6 \%$ of girls and $5.9 \%$ of boys claimed to have visited such sites (Custers and Van den Bulck 2009). Yet within the prevention project meetings and sessions 'pro-anorexia' was never engaged with. Neither websites nor advocacy of anorexia as a lifestyle choice was acknowledged or discussed. Given that the project engaged with a similar age range to the study mentioned above, 1319 year olds, this elision of online life as an aspect of real life is indicative of the way the project conceived the problem. Anorexia was considered as a mental illness, but one to which young people could be resilient to if they had high levels of self-esteem. Although the intervention thus acknowledged sociocultural factors associated with eating difficulties, social life was conceived of in terms of offline 'real life'. This notion of what is real and not real (see Markham 1998) forecloses the possibility of fully engaging with the complex and nuanced aspects of conformity and resistance within difficult relationships to feeding the body. As such, I will argue below, the project was limited in its capacity to fulfil its 'preventative' logic.

Pedagogical and ethical issues

As the project developed work began with partner organisations such as schools and youth clubs. Here both ethical and pedagogical issues became apparent which were beyond the control of either the prevention project or myself as aparticipant observer. It is worth discussing these in some detail, as they not only signal the practical problems that intervention projects may face when they attempt to work with schools, but also raise important questions about the ways in which adult professionals engage with young people who may be experiencing health and body issues.

During the initial mapping phase of the prevention project, two girls'schools had been identified as including students who were experiencing issues with both eating disorders and self-harm. However, at one of these schools, the students ultimately assigned to the 
weekly project sessions were girls who had been removed from formal classes for behavioural issues. Aged between 12 and 15, the pupils who turned up to the project sessions varied from week to week, depending on who had been in trouble in class.

At the second girl's school, which had a reputation for success at GCSE and A Level, the head of PSHE was reluctant to release students from classes during school hours on the grounds that they would miss valuable lessons, and equally unwilling for them to miss valuable CV-enhancing extra-curricular activities. In the end, after telephone calls and visits by myself and the lead youth worker, school staff decided that they would not work with the prevention project. Similar to what was found at the first all-girl school mentioned above; in one of the mixed schools which took part students were released to attend the project in place of a regularly scheduled religious education class. In none of these instances were the young people themselves given the opportunity to opt in or out, despite the fact that the prevention project staff had stressed voluntary participation as an ethical imperative. Moreover, although information and consent forms had been sent to schools weeks in advance, students had not been told why they were involved in the project, for how long, why they were missing their religious education classes, etc.

There were problems for the project therefore, in accessing the population of students identified as in need of the intervention and in engaging students who had made an informed decision to take part. Moreover, it seemed clear that the intervention project was given a low priority by schools driven by state-mandated policies that prioritise academic achievement. The prevention project often seemed to be viewed either as an unfortunate distraction from the core business of curriculum instruction, or as a resource to fill gaps or occupy young people identified as a problem in class. Despite the widespread perceptions of the serious risks of disordered eating among young people, discussed above, the prevention project was perceived as low status, with serious implications for ethical participation, and ultimately, for the success of the project. I return to the implications of this in the conclusions. For the moment, I wish to move to a discussion of the pro-ana sites involved in the research.

\section{The pro-ana sites}

During this same period I had 'arrived' in the virtual field and begun to follow the discussion boards of seven pro-ana sites. Following the ethical guidelines produced by the Association of Internet Researchers (AOIR 2002), ${ }^{3}$ it was decided that only exchanges in publicly accessible forums and discussion boards would be accessed. At the initial stage of the research, each of the siteswas conceived of as textual as the only aspect viewed were archives of the public-and-private discussion boards. Kozinets suggests that for the purposes of research ethics we can 'regard the use of some types and uses of computermediated cultural interactions as similar to the use of texts' $(2010,142)$. All of the sites that were observed throughout the study had private inbox functions as well as public or communal discussion boards. Although I was treating the 'data' as textual, I remained mindful of issues of anonymity and confidentiality and as such carried out 'heavy cloaking' (Kozinets 2010). In practice this meant that all of the data copied and pasted to Word documents for early and provisional analysis was changed immediately: names of sites were changed, as were pseudonyms and all user profile pictures were deleted. As with Day and Keys' method, I 'lurked' $(2008,5)$. This meant that no attempts were made by me to deceive those visiting the sites by, for example, pretending to be someone who had an interest in seeking advice on weight loss or learning how to have a more ascetic relationship to feeding the body. Lurking is not an uncommon online practice; indeed, 


\section{S. Dyke}

Conrad and Stults (2010) note that for every active member there are likely to be another twenty 'lurking'. In research practice lurking meant being present, but not actively representing myself.

As there was already an abundance of comments and questions on the publicandprivate discussion boardswhich would inform the questions I wished to take to offline spaces, a decision not to invite members to respond to questions I had formulatedwas both strategic and ethical. Although I did not subsume online life under offline life, ethically I did not want to disturb the community interaction by potentially becoming another form of surveillance (Fox, Ward, and O' Rourke 2005) or disrupting what for somewas consideredasanctuary(Dias,2003).Although itispossibletogaininformed consent in netography (Kozinet 2010), as a feminist researcher aware of the risks involvedintalkingaboutrisk-takingactivitieslikeanorexia,itwasimportantfor meto negotiate ethics and consent as an ongoing process with participants, and I felt best abletodoinafaceto-facecontext.Aswillbecomeapparentlaterinthepaper,byusing connective ethnography and following the flowof ideas, concepts and phenomenon to different spaces, I was able to meet a member of the pro-ana community offline.

The seven pro-ana sites were explored for postings which attracted both a significant amount of comments from various members of the community and had been contributed to over a time period of more than one month. The field notes which were based on these spaces were an extremely significant tool in terms of working ethically and reflexively, and also noting connections between people, places, ideas and communities. In other words, my field notes not only provided a record of time spent in a particular site, but they also recorded how I had got there. They enabled a reflexive interrogation of the circumstances which lead me to be 'telling this story about this object at this time and in this way' (Hine 2000, 57).

Oneofthemostimportantissuesthisrecordmademeawareofwasthedifferentway inwhichtextsandmovingbodies(Massumi2002)affectedme.Asmentionedpreviously, proanasiteswereregardedatthisstageofthe researchastextual,andalthoughthiswas a decision based on my capacity to work ethically with others, the distance this kind of engagement permitted was also a means to 'protect' myself as a researcher from being 'alone' in abject, emotive and 'risky' spaces. Although I never forgot that the textual accounts came from embodied subjects, there was something distinct about my engagement with the moving body, as can be noted in the extract below.

April 2011:

Involuntary tears and a painful lump to my throat after following a series of about ten 'ana' clips on youtube: I've had to stop. The last was edited to a song I like and it was too much. It followed a series of hollow eyed facial shots taken in various mirrors, in various spaces including public toilets. The face was disrupted by footage of footsteps across different terrains and in different shoes. The face was so wretched and pained I wanted to press pause, but I was worried what the image I fixed on screen would be.

My responses to these publically accessible images, moving and fixed, became important for me to explore and reflect on off-line; both in the questions I took to other sites and also the theoretical framework which I drew on (Massumi 2002).

\section{Bordering the field}

The decision to focus on particular themes helped me to border the virtual field by gradually narrowing my search to communal discussions which engaged with the idea of 
whether anorexia was a lifestyle choice or a mental illness. To refer back to the quote given by Hine (2000) at the start of this section, within these threads another word had become meaningful and visible, and so it was also followed. The word was 'wannarexia'; a word which conflates the 'proper name' anorexia with the phrase 'wannabe'. In other words, wannarexic's want-to-be-proper anorexics. Although this improper name is most commonly used as a pejorative term for those who 'fake' anorexia, giving it; and the proana community a bad name and diminishing levels of trust among site members (Giles 2006), it was also mobilised by members of the community who wished to acknowledge a degree of complicity with their anorexic becoming. This acknowledgement of collusion and desire can be connected to a desire to bring about something which may have already been in movement and which is incremental in its becoming. In other words, acknowledging desire and movement disrupts the cultural freeze framing of both media and medical representations of anorexia as synonymous with a particular weight or appearance.

No one who is anorexic starts having food problems when they are already at an anorexic weight. We all start somewhere, and we are all different. (sw B3B3tboy)

I was a wannarexic, I tell others that want the eating disorder about my story, how I wish I could go back to the day where I looked at my first pro-ana website, how fucking stupid I was. Maybe I already had it though, I do think wannarexics have the start of an eating disorder but maybe someone could maybe talk them out of it but I don't think anything would of scared me off, only if I saw myself now, that would of changed my mind. (strangeasangels95)

the term wannarexic is ppl who eat normally, untill they want to drop some lbs and goes for this as a diet, and try to be this. (Psychocandy)

Yes, I agree - eating disorders DO start somewhere but the ones who have that mental component won't be crash dieting. People who lie and claim to have an illness just for the 'social status' that's what I think it means. (Eleph\&ntwom\&n)

While the prevention project did not put me in direct contact with participants who might be able to give an 'everyday account' of the phenomenon, it did lead me to other sites, people and ideas. It also highlighted that the exclusion of online life as an aspect of real life was detrimental to both research and practice. One of the sites the prevention project bought me into contact with was a feminist archiving project, also based in the north of England. Through this site a detailed pro forma, giving the details of my research aims, what would be asked of potential participants, and what they could expect from me in terms of rights to anonymity, confidentiality and ethical treatment, was disseminated to a thousand youth workers, feminists and young people. Of the thousand inboxes to receive the email there was one response. This apparent reluctance to engage offline with the issue of a difficult relationship to feeding the body was striking in its contrast to the number of people who I had seen engaging with similar themes online. Indeed between March 2011 and March 2012 my search results for *pro ana* into the publically accessible site YouTube increased by $25 \%$ from just below 18,000 to just over 23,000.

The blended method and the face-to-face meeting

Six weeks and three hushed telephone calls after the first email was sent, I met a young feminist called Joanne. Below is an account of our first meeting through field note excerpts. Following the vivid and embodied account Markham (1998) gives of research 


\section{S. Dyke}

and life online, I incorporate these notes to draw attention to the way in which the field diary remains essential to the ethnographic process when the field is also constituted by virtual spaces.

15 March 2011:

$2.30 \mathrm{pm}$

Waiting for Joanne, it feels as though it's been a long time coming. The first call she had made was while I was en route to one of the schools the prevention project was working with. My plan is to introduce myself, my work and take it slowly. I also want to ask her why she has come forwards given that it appears to be a secret she keeps from her partner. I wonder what her story is.

$5 \mathrm{pm}$

The meeting went really well. Joanne has seven years of experience with anorexia and pro ana. While she was still at school she had set up a pro-ana forum under the guise of a creative writing group meaning that the space was unlikely to be 'moderated' or 'closed down'. Joanne is keen to convey the 'everyday-ness' of having a difficult relationship with the body and has agreed to contribute over time.

\section{$7.15 \mathrm{pm}$}

Just home and looked through some emails, opened Facebook to see if my sister is online and Joanne has sent me a friend request. I can't help but read into this that that today was a good experience for her and that she is interested in the research. I've accepted the request but had to make a few decisions in situ. I have decided that if Joanne uses Facebook to contact me I will respond quickly and ask if it is research related and therefore possible data. I will not contact her first or write on her publically viewable Facebook wall. I don't want her to feel as though me, or the research, are

'everywhere'.

These excerpts draw attention to the field diary as a tool which not only records where we have been, but also how we have got there through offline and online spaces. The field diary in the context of a blended methodology provides a means to critically reflect on ethical issues which become apparent as field work develops and as we move through online to offline life. As an incremental process mobile or connective ethnography cannot predict at its inception all of the ethical considerations it may need to, to protect either the researcher or the participants who come forward over time. Therefore, as the project moves the field diary engenders a significant space for ethical reflection and decision-making.

Before we had met Joanne had been clear that she would always contact me first as her partner was not aware of the way that anorexia had become meaningful to her again. I was highly aware of the risks she was taking in coming forward; as such the first meeting was an important opportunity to discuss the ethics and politics of the research. Although it is possible to obtain informed consent online (Kozinet 2010), I felt most equipped to carry out these ethical procedures in a faceto-face context. As we talked about the boundaries of my field; what I wanted to find out about, what my questions were, I also wanted Joanne to feel confident that her engagement with the research field had boundaries. The final sentence of the excerpt above indicates the way in which reflexive ethical decisions were made to ensure that Joanne did not feel that either myself, or the research, was 'unbounded'.

During the weeks and months that followed the first meeting, I continued to look at pro-ana discussion boards and attend the workshops which the prevention project ran. I 
also continued to meet Joanne both face-to-face and through her Facebook status updates. ${ }^{4}$ Recently the upload of popular music videos and 'light hearted' comments had given way to statistics which came from her weight tracker phone application (app). 'Joanne has burned 223 calories from 60 minutes' swimming. She has lost 2.5 lbs since her last weigh in'. As we talked, it became clear that her daily practices were, in her own words 'utterly dependant' on technologies which enabled her weight management: exercise bike, pedometer, kitchen scales, bathroom scales, website to calculate calorific intake/output. Joanne said that she had realised her dependence on these technologies when she could not afford to pay the subscription to the site that she used to record her calorie intake and energy expenditure. Everything she did and consumed offline was entered online, reinforcing both the idea that the virtual is by no means the end of corporeal subjectivity (Keeps cited in Markham 2008) and that online life was a significant part of Joanne's reallife experience (Markham 1998), particularly the way she communicated and expressed (Kozinet 2010) her disciplined body. Although she did not mention at this point pro-ana spaces, her Facebook status update a week later alerted me to the fact that this may be another online activity we might engage with face to face.

How weird that I've been able to find my old friends on a completely different site; if they don't kick my butt into gear, no-one will! (Joanne, Facebook update)

My field notes which follow the next meeting note that talk had 'hardened' and that Joanne was increasingly invested in attaining a BMI which would make her a 'real' or proper anorexic' again.

May 19th:

$6 \mathrm{pm}$

We talked about the pro ana involvement and she said that it was distinct to other social networking sites. She said that the one that she was using still had many of her 'pro ana peers' on it. She gave me the site name but it might be 'fake'. She lost focus on a few occasions and wasn't able to concentrate or recollect the question I had asked. I knew that there would be more of this to come. She wasn't acknowledging bodily indicators until she was thin enough to recognise them as part of anorexia, until she met the DSM criteria of $85 \%$ or reached a BMI of less than 18 .

Returning home late I decided to look at 'Fragile Beauty' the site Joanne had mentioned in our face-to-face meeting. However, when I tried to search for it the result suggested it was 'unavailable' and I should 'try again later'. I wondered whether or not the site had been 'moderated' or closed down, as is so often the case (Dias 2003) and went back to sending Youtube video clips to my sister on Facebook. Because Joanne was a Facebook friend I was privy to her update when I refreshed my page. 'I'm trying to log on to a site, but it seems to be down...making me panic a little' (Joanne's Facebook update). Knowing the site had not been closed I tried to access it the next day, I found that Joanne had only joined very recently, but in that time had been part of in excess of 100 discussions. Because I had an affective sense of Joanne from our face-to-face meetings, my engagement with this site felt different to the other seven. This sense of Joanne had much to do with her being in movement and also recalls my response the YouTube clip discussed earlier. I could conjure to mind, and sense within my body, the way Joanne put her hands over her mouth when she spoke of binges and how this made me feel, how her face looked when tears began to emerge and how her always gentle voice had become significantly quieter recently. 


\section{S. Dyke}

All of this face-to-face information informed my reading of her comments and avatar. The evening before our next meeting, the Fragile Beauty avatar, a head shot of her 14year-old self, became her Facebook profile picture. As Joanne immersed herself in the proana community once more, it became the focus of our face-to-face discussions. Here she was also able to tell me that she had joined an 'invitation only' Facebook group. Set up by UK members of Fragile Beauty, the group's name was never imparted to me by Joanne but the issues which came up there were.

$\mathrm{J}$ : The group was set up because of the UK meet last year so they set it up so they could meet more easily.

S: Meet? Do you know anything about that? It sounds really interesting.

$\mathrm{J}$ : it was a while ago that one but they have been having them a lot more regularly because some of them are really good friends, I was meant to go to one this weekend but....

S: You didn't go? I'm just wondering what happens.

J: It's not focussed on eating, they won't focus on what other people eat and they just sort of focus on everyday life which is where we all don't particularly eat very much and we all restrict anyway and it's just helpful knowing that everyone else has problems with having to eat. No one questions you if you don't eat before you go out or anything.

The idea that the online community met offline was fascinating in terms of contesting notions of anorexia only as an individual and individualising mental illness, while also troubling those forecasts which had considered the virtual as the 'apocalypse of corporeal subjectivity' (Keeps cited in Markham 2008, 252). Rather, this move to the face-to-face reinforced the idea that to be pro-anorexic was communally meaningful. For Joanne and others in the group, this communal meaning was at least in part due to the emotional spatiality of what might usefully be referred to as the field of anorexia. In other words, both face-to-face and online meetings made it possible to engage with others who had 'been there' and had their own stories of first-hand witness to share.

From this it became apparent that the pro-ana community was itself mobile; moving to spaces which become meaningful and blending online and offline methods of meeting and data sharing. This connection between theory, research and pro-ana practices became increasingly apparent as both myself and Joanne experienced the closure of 'Fragile Beauty'. Rather than a decision to 'leave the field' in a timely and ethically appropriate manner, part of the 'field' left us. For both of us this inferred no more data collection from this site, for me discussion boards, for Joanne the private inbox messages she wanted to save.

S: So i was looking at the website the other day and noticed that it was down, what's happening?

J: It's completely closed down [...] it was a big shock and I think that a lot of people took it hard. But because I mainly used the Facebook group, and so did the people that I talked to it wasn't so bad...But I mean I did rely on it quite a lot, I didn't realise how much I relied on the site for support and stuff but I still have my friend Facebook group. The whole thing is gone now [...] completely deleted...our messages and everything are gone. I was gutted because she shut it a day early and I wasn't able to go on and copy and paste stuff that I wanted to keep.

A bond of trust has been abused, something of value maybe lost... 
If identity play is as wide as is suggested, this might be expected to have some impact on the extent to which people trust one another, and the ways in which they treat the internet as a reliable source of information. (Hine 2000, 119)

Although whether or not ana and anorexia can be seen as the same discursive object (Giles 2006) is debatable, rather than investing in either, as real or unreal, we might instead explore the ways in which the Internet makes identities available and possible. Earlier I introduced the phrase 'wannarexia' and how it had emerged as meaningful in the context of discussions about whether anorexia was a lifestyle choice or a mental illness, a theme which had helped to border the online field. While for sw B 3B3tboy 'wannarexia' was where anorexia starts, and strangeasangels 95 acknowledged a degree of collusion with the desire that anorexia mobilised, Psychocandy's suggestion indicated the reification of anorexia or 'this', as real and desirable. Rather than conceiving of a difficult relationship to feeding the body, which infers praxis or 'doing' Psychocandy considers anorexia as an authentic ontological position that wannarexics can only ever 'try to be'. Eleph\&ntwom\&n's suggestion that because anorexia has kudos, people who have no rightful purchase on the position, those who have not earned the mantle, claim it for the purposes of 'social status'. I draw attention to 'wannarexia' again as it returns me to the earlier ideas of internal antagonism and contestation (Giles 2006) and also as it is relevant to Joanne's account of what happened in the Facebook group she relied on after the closure of Fragile Beauty.

S: What things have you been talking about online recently?

J: There has been this girl who was part of Fragile Beauty [who] got invited to the Facebook group, but she basically faked [...] being really ill [...]. Like if you look back at some of her comments, her symptoms were basically what she was copying off this other girls so it was just offensive [...]. I've met about eighteen of them at different meets and there are about thirty of us in the Facebook group who've all met one another somehow, even if it's through a third party.

S: So I was thinking about faking it, what does that mean? Do you think that what she has done gives pro ana's and the community a bad name?

$\mathrm{J}$ : Yeah, definitely, no one wants to be seen as an attention seeker or anything [...]. People are still really, really uncomfortable and there are at least a couple of people that have barely posted since it happened [...] it's got a lot more strict because there were a few people on the site that were not using their real Facebook account, they were setting up new ones with silly ana names but now you can only join if you are willing to use your own account, so if it turns out that you are not who you said you were then it could almost be used against you, so basically you are showing more trust if you are using your own username.

S: How common do you think this might be? How many people do you think 'fake'?

J: I'd say quite a lot. I don't know because you can't say for definite that someone does or does not have those types of issues [...] it's part of the reason that I prefer Facebook because I know who most of the people are.

This internal antagonism can be seen to affect levels of trust online which in turn, and perhaps paradoxically, engendered an offline or real-life bias among the pro-ana group. Also, as can be seen above, the idea of the real Facebook profile can be seen to be so ingrained in daily praxis that it becomes the guarantor of a trustworthy proana. As 


\section{S. Dyke}

guarantor, rather than guarantee, the real Facebook profile faces repercussions if the proana is identified as improper: a 'fake' or a 'wannarexic'.

Concluding comments and thoughts for future educational research

This paper has drawn attention to the way in which the blended method (Kozinet 2010) can be used to follow connections which become incrementally meaningful through the course of the research process. By following the object of inquiry to different spaces, online and offline, a more attentive methodology was developed which reflected the complexity of the phenomenon and provided a more evocative account of the sociohistorical, and technologically mediated, context in which anorexic becomings now occur.

I have consistently argued in this paper that life online be regarded within the context of 'real' or everyday life, and its practices. I have also bought to bear a nuanced account of free will and determinism by considering a productive paradoxical relationship between different expert discourses. Here, rather than fixing lifestyle choice and mental illness as a logical contradiction I have highlighted the way in which embodied experience and medical expertise brush up against one another to engender collusion, resistance and contestation. By incorporating this tension and ambivalence into my work I also highlight the way themes, rather than fixed spaces, can be used to border the field of ethnographic inquiry.

By engaging with anorexia in the context of the prevention project I was able to highlight the shortfall incurred by failing to engage with life online. I was also able to suggest that social researchers, and youth practitioners, should engage with issues of embodiment in ways which acknowledge the complexity of desire, collusion and communally meaningful identities. The rigidity of the prevention project was shown to be in contrast to the pro-ana community who blurred the boundary of an online community by blending it with offline activities. Here the virtual domain which enabled, rather than foreclosed, face-to-face gathering can be seen to trouble Keeps suggestion that computermediated communication hailed 'the apocalypse of corporeal subjectivity' (Markham 2008, 252).

As noted in the section of the paper which focused on pedagogical issues, the intervention projects collaboration with schools and youth centres drew attention to the failure of some settings to properly gain informed consent from the young people they worked with. Also, while only one of the schools identified as having a high level of need agreed to take part, the young people who were allocated to the sessions changed from week to week and were comprised of those who had been removed from other, formal, lessons.

Methodologically mobile and connective ethnography is agnostic to real places and identities, and as such I did not only seek participation from 'proper' diagnosed anorexics in 'proper'spaces, such as the clinic. Instead, and as the paper makes clear, I became sensitive to spaces, themes and ideas which became meaningful during the ethnographic process. In working this way I was able to draw attention to the way in which powerful discourses, such a medicine and science, continue to organise communities who attempt to resist and disrupt dogmatic definitions given to them. In highlighting the way in which traditional medical expertise offline is both contested and colluded with by experience based experts online; my work suggests that epistemologies of embodiment blend as they brush up against one another, merging to produce different possibilities and alternative antagonisms. 
In terms of what constitutes the field in a blended methodology, the paper draws attention to the way in which the incorporation of virtual spaces, ideas, themes and communities makes the issue of bordering more, rather than less, important. Because the mobile or connective method is not fixed from inception, and the points where online life and offline life connect cannot be predicted, a high level of reflexivity and rigour is required on the part of the researcher. In this paper I have argued that the field diary is an integral tool which records not only where we have been, but also how we have got there. Field notes, in the context of blended and mobile methodology, provide a means to critically reflect on ethical practice, which only becomes apparent as the project develops.

In terms of future educational research and blended methodological practices, online life presents us with an opportunity to develop sensitive and trenchant understandings of communally meaningful identities which are both resistant to, and informed by, demanding categories such as gender, sexuality and educational achievement. Just as 'the offline world [...] structures and provides reference points for online interactions' (Hine $2000,144)$, the ethnographic community may do well to become mindful of the way in which online interactions increasingly become reference points for offline embodied relationships.

\section{Notes}

1. The fourth criterion, which explicitly links anorexia to biological females, is currentlyundergoing review by the DSM-V Task Force and the Eating Disorders Work Group (Walsh, 2009).

2. Child and Adolescent Mental Health Services is structured in a four-tiered model, althoughthe tiers are not neatly differentiated. Tier 1 is the primary care that is provided by professionals who are not mental health specialists, for instance, school nurses, teachers and social workers (Spratt et al 2010).

3. The Association of Internet Researchers is an academic association which is internationalin scope and works to advance the cross-disciplinary field of Internet studies. It is a member-based support network promoting critical and scholarly Internet research which exists across academic borders. The Ethics Working Group has produced a report to assist researchers in making ethical decisions in their research which was approved by voting members on 27 November 2002. http://aoir.org/about/ [Accessed 2 April 2012].

4. Facebook users overwrite the text 'what's on your mind' with comments, thoughts andhyperlinkstomusicvideos,politicalblogs,newsfeedsandotherthingsthatare'ontheirmind'.

\section{References}

American Psychiatric Association. 2000. Diagnostic and Statistical Manual of Mental Disorders. 4th ed. Washington, DC: American Psychiatric Association.

Association of Internet Researchers. 2002. "Ethical Decision-Making and Internet Research: Recommendations from the AOIRWorking Committee." Accessed January 15. http://www. aoir.org/reports/ethics.pdf

Bray, A. 1996. "The Anorexic Body: Reading Disorders." Cultural Studies 10 (3): 413429. doi:10.1080/09502389600490251.

Chaote, L. H. 2005. “'Towards a theoretical Model of Women's Body Image Resilience.' Journal of Counselling and Development 83: 320330.

Collins, H. M., and R. Evans. 2002. “The Third Wave of Science Studies: Studies of Expertise and Experience.”' Social Studies of Sciences 2 (32): 235296. doi:10.1177/03063127020 32002003.

Conrad, P., and C. Stults. 2010. "The Internet and the Experience of Illness.' In Handbook of Medical Sociology. 6th edn, edited by C. E. Bird, P. Conrad, A. M. Fremont and S. Timmermans, 179191. Nashville: Vanderbilt University Press. 
160 S. Dyke

Custers, K., and J. Van den Bulck. 2009. "Viewership of Pro-Anorexia Websites in Seventh, Ninth and Eleventh Graders.” European Eating Disorders Review 17 (3): 214219. doi:10. 1002/erv.910.

Darmon, M. 2009. "The Fifth Element: Social Class and the Sociology of Anorexia." Sociology 43 (4): 717733. doi:10.1177/0038038509105417.

Day, K., and T. Keys. 2008. "Starving in Cyberspace: A Discourse Analysis of Pro-EatingDisorder Websites." Journal of Gender Studies 17: 115. doi:10.1080/09589230701838321.

Dias, K. 2003. "The Ana Sanctuary: Women's Pro-Anorexia Narratives in Cyberspace." Journal of International Women's Studies 4 (2): 3145. http://vc.bridgew.edu/jiws/vol4/iss2/4.

Ferreday, D. 2003. 'Unspeakable Bodies: Erasure, Embodiment and the Pro-ana Community.' International Journal of Cultural Studies 6 (3): 277295.

Fox, N., and K Ward. 2006. 'Health Identities: From Expert Patient to Resisting Consumer.' Health 10: 461479 .

Fox, N., K. Ward, and A. O' Rourke. 2005. "Pro-Anorexia, Weight-Loss Drugs and the Internet: An 'Anti-Recovery' Explanatory Model of Anorexia.' Sociology of Health and Illness 27 (7): 944971. doi:10.1111/j.1467-9566.2005.00465.x.

Gavin, J., K. Rodman, and H. Poyer. 2008. “The Presentation of 'Pro-Anorexia in On-line Group Interactions.” Qualitative Health Research 18 (3): 325333. doi:10.1177/1049732 307311640.

Geertz, C. 1993. The Interpretation of Cultures. London: Fontana.

Giles, D. 2006. "Constructing Identities in Cyberspace: The Case of Eating Disorders." British Journal of Social Psychology 45 (3): 463477. doi:10.1348/014466605X53596.

Gremillion, H. 2003. Feeding Anorexia: Gender and Power at the Treatment Centre. Durham: Duke University Press.

Hammersley, M., and P. Treseder. 2007. “'Identity as an Analytic Problem: Who's Who in 'Pro-ana' Websites?' Qualitative Research 7 (3): 283300. doi:10.1177/1468794107078509.

Hine, C. 2000. Virtual Ethnography. London: Sage.

Klump, K. L., C. M. Bulik, W. H. Kaye, J. Treasure, and E. Tyson. 2009. “'Academy for Eating Disorders Position Paper: Eating Disorders are Serious Mental Illnesses." International Journal of Eating Disorders 42 (2): 97103.

Kozinets, R. V. 2010. Netnography: Doing Ethnographic Research Online. London: Sage.

Lawrence, M. 1987. "Education and Identity: The Social Origins of Anorexia." In Fed-up and Hungry: Women, Oppression and Food, edited by M. Lawrence, 207225. London: Women's Press Limited.

Markham, A. N. 1998. Life Online Researching Real Experience in Virtual Space. Oxford: AltaMira Press.

Markham, A. N. 2008. "The Methods, Politics, and Ethics of Representation in Online Ethnography.' In Collecting and Interpreting Qualitative Materials. 3rd edn, edited by N. Denzin and Y. Lincoln, 247284. London: Sage.

Massumi, B. 2002. Parables for the Virtual: Movement, Affect, Sensation. Durham: Duke University Press.

McGee, R., and S. Williams. 2000. "Does Low Self-Esteem Predict Health Compromising Behaviours among Adolescents?" Journal of Adolescence 23 (5): 569582. doi:10.1006/ jado.2000.0344.

Miah, A., and E. Rich. 2008. The Medicalisation of Cyberspace. New York: Routledge. Mulveen,

R., and J. Hepworth. 2006. " An Interpretative Phenomenological Analysis of Participation in a ProAnorexia Internet Site and Its Relationship with Disordered Eating." Journal of Health Psychology 11 (2): 283296. doi:10.1177/1359105306061187.

Murthey, D. 2008. "Digital Ethnography: An Examination of the Use of New Technologies for Social Research." Sociology 42 (5): 837855. doi:10.1177/0038038508094565.

Optenet. 2008. “International Internet Trends Study." [online]. Optenet. Accessed March 12. http://www.optenet.com/mailing/pdfs/TrendReport.pdf.

Pollack, D. 2003. "Pro-Eating Disorder Websites: What Should be the Feminist Response?' Feminism and Psychology 13 (2): 246251. doi:10.1177/0959353503013002008. 
Rheingold, H. 1993. The Virtual Community: Homesteading on the Electronic Frontier. Reading, MA: Addison Wesley.

Rich, E. 2006. "Anorexic (Dis)connection: Managing Anorexia as an Illness and an Identity." Sociology of Health and Illness 28 (3): 284305. doi:10.1111/j.1467-9566.2006.00493.x.

Royal College of Psychiatrists. 2009. Eating Disorders: Key facts from the Royal College of Psychiatrists. Accessed June 14, 2010. www.rcpsych.ac.uk.

Spratt, J., K. Philip, J. Shucksmith, A. Kiger, and D. Gair. 2010. "'We are the Ones that Talk About Difficult Subjects Nurses in Schools Working to Support Young People's Mental Health." Pastoral Care in Education 28 (2): 131144. doi:10.1080/02643944.2010.482145.

Walsh, T. B. 2009. "Eating Disorders in DSM-V Review of Existing Literature (Part 1)." International Journal of Eating Disorders 42: 579580. http://onlinelibrary.wiley.com/doi/10. 1002/eat.20756/pdf.

World Internet Statistics. 2012. "World Stats Usage and Population Statistics.” Accessed October 24. http://www.internetworldstats.com/stats.htm 